\title{
Clinical and epidemiological study of EGFR mutations and EML4-ALK fusion genes among Indian patients with adenocarcinoma of the lung
}

This article was published in the following Dove Press journal:

OncoTargets and Therapy

5 January 2015

Number of times this article has been viewed

\author{
DC Doval' \\ K Prabhash ${ }^{2}$ \\ S Patil ${ }^{3}$ \\ $\mathrm{H}_{\text {Chaturvedi }}{ }^{4}$ \\ C Goswami ${ }^{5}$ \\ AK Vaid ${ }^{6}$ \\ S Desai ${ }^{2}$ \\ $S$ Dutt $^{7}$ \\ VH Veldore ${ }^{8}$ \\ $\mathrm{N}$ Jambhekar ${ }^{2}$ \\ A Mehta' \\ D Hazarika ${ }^{8}$ \\ S Azam' \\ S Gawande 9 \\ S Gupta ${ }^{10}$
}

'Rajiv Gandhi Cancer Institute and Research Centre, New Delhi, ${ }^{2}$ Tata Memorial Hospital, Mumbai, ${ }^{3}$ Bangalore Institute of Oncology, HCG Group, Bengaluru, ${ }^{4}$ Max Super Speciality Hospital, New Delhi, ${ }^{5}$ B. P. Poddar Hospital, Kolkata, ${ }^{6}$ Medanta The Medicity, Gurgaon, ${ }^{7}$ Oncquest Laboratories Ltd., New Delhi, ${ }^{8}$ Triesta Reference Laboratory, HCG Group, Bengaluru, ${ }^{9}$ Pfizer India Ltd., Mumbai, ${ }^{10}$ Catalyst Clinical Services Pvt. Ltd., New Delhi, India
Correspondence: Dinesh Chandra Doval Department of Medical Oncology, Rajiv Gandhi Cancer Institute and Research Centre, Sector V, Rohini, New Delhi, I 10085 , India

Tel +9l II 47022252

Email dcdoval@gmail.com
Background: Mutation in the tyrosine kinase domain of epidermal growth factor receptor (EGFR) is a common feature observed in lung adenocarcinoma. A fusion gene between echinoderm microtubule-associated protein-like 4 (EML4) and the intracellular domain of anaplastic lymphoma kinase (ALK), named EML4-ALK, has been identified in a subset of non-small-cell lung cancer (NSCLC) tumors. The objective of this study was to determine the prevalence of EGFR mutations and EML4-ALK fusions in Indian patients with NSCLC (adenocarcinoma) as well as evaluate their clinical characteristics.

Patients and methods: Patients with NSCLC, adenocarcinoma histology, whose tumors had been tested for EGFR mutational status, were considered for this study. ALK gene rearrangement was detected by fluorescence in situ hybridization using the Vysis ALK Break Apart Rearrangement Probe Kit. ALK mutation was tested in samples that were negative for EGFR mutation. Results: A total of 500 NSCLC adenocarcinoma patients were enrolled across six centers. There were $337(67.4 \%)$ men and 163 (32.6\%) women with a median age of 58 years. One hundred and sixty-four (32.8\%) blocks were positive for EGFR mutations, whereas 336 (67.2\%) were EGFR wild-type. Of the 336 EGFR-negative blocks, EML4-ALK fusion gene was present in 15 (4.5\%) patients, whereas $321(95.5 \%)$ tumors were EML4-ALK negative. The overall incidence of EML4-ALK fusion gene was 3\% (15/500).

Conclusion: The incidence of EGFR mutations (33\%) in this Indian population is close to the reported incidence in Asian patients. EML4-ALK gene fusions are present in lung adenocarcinomas from Indian patients, and the 3\% incidence of EML4-ALK gene fusion in EGFR mutation-negative cases is similar to what has been observed in other Western and Asian populations. The mutual exclusivity of EML4-ALK and EGFR mutations suggests implementation of biomarker testing for tumors harboring ALK rearrangements in order to identify patients that can benefit from newer targeted therapies.

Keywords: NSCLC, Crizotinib, Vysis ALK Break Apart Rearrangement Probe Kit

\section{Introduction}

Lung cancer is one of the leading causes of cancer-related death in many parts of the world, including India. The overall 5-year survival rate remains at $15 \%$ despite significant improvements in the detection and treatment of lung cancer. ${ }^{1}$ Treatment outcomes using various chemotherapy (eg, taxane, platinum, gemcitabine, vinorelbine, pemetrexed) remain poor for advanced non-small-cell lung cancer (NSCLC). ${ }^{2}$ Adenocarcinoma is the most commonly occurring form of NSCLC and usually presents at an advanced stage with limited treatment options.

The introduction of targeted therapies into the treatment of NSCLC has improved survival of patients. However, it needs an accurate histological classification as 
well as testing of tumors for biomarkers that are predictive of response. Activating mutations in exons 18-21 of the tyrosine kinase domain of the gene for epidermal growth factor receptor (EGFR) are known to correlate with a high likelihood of response to EGFR tyrosine kinase inhibitors (TKIs), and these findings have paved the way for a new era of personalized treatment for NSCLC. ${ }^{3,4}$

Recently, a fusion gene between echinoderm microtubuleassociated protein-like 4 (EML4) and the intracellular domain of anaplastic lymphoma kinase (ALK), named EML4-ALK, has been identified in some NSCLC tumors. ${ }^{5,6}$ EML4 ALK fusion protein, when inhibited by ALK and $\mathrm{c}$ met inhibitors in a selected subset of patients, has shown response rates of more than $60 \%$.

In an East Asian population, the EML4-ALK fusion gene positivity was found to be $5 \%$, mostly in young patients who were never-smokers. ${ }^{8}$ However, a higher incidence of ALK mutations was reported in Chinese NSCLC patients, particularly in those with adenocarcinoma lacking EGFR/KRAS mutation. EML4-ALK and EGFR mutations were mutually exclusive, suggesting that ALK mutations may be an important oncogenic factor and a potential therapeutic target in EGFR wild-type lung cancer. ${ }^{6}$

An oral ATP-competitive TKI of ALK and c-MET, crizotinib (PF-02341066), has shown impressive clinical activity in advanced NSCLCs, especially in tumors harboring ALK rearrangements. An impressive response rate of 57\% and $72 \%$ progression-free survival were seen in an expanded cohort of 86 patients treated with crizotinib $250 \mathrm{mg}$ twice daily. All these patients were negative for EGFR mutation and amplification of MET, another target for crizotinib, which suggests the therapeutic effect through inhibition of ALK. ${ }^{9}$ Treatment with crizotinib has been associated with higher 1 - and 2 -year overall survival, of $77 \%$ and $64 \%$, respectively, in patients with advanced NSCLC. ${ }^{10}$ Crizotinib has been reported to be safe, with preliminary evidence of improved symptoms and clinically meaningful antitumor activity in patients with pretreated ALK-rearranged NSCLC. ${ }^{11}$ In a Phase III, open-label trial comparing crizotinib with chemotherapy in locally advanced or metastatic ALK-positive lung cancer patients, crizotinib demonstrated a median progression-free survival of 7.7 months, as compared to 3 months in the chemotherapy group $(P<0.001)$. The response rates were $65 \%$ with crizotinib compared to $20 \%$ in the chemotherapy group $(P<0.001) .{ }^{12}$

Various studies of NSCLC patients of Indian ethnicity have reported the presence of EGFR mutations in the range of $23 \%-44 \% .{ }^{13-15}$ However, there is only one published report from India on EML 4 ALK mutations, with a limited number of patients. ${ }^{16}$ Although the presence of EML 4 ALK mutation seems to be mutually exclusive of the presence of EGFR or KRAS mutations in NSCLC, there are a few reports of concurrent existence of both the mutations. ${ }^{17-19}$ The present study was carried out to detect the prevalence of EGFR mutations and EML4-ALK fusions in EGFR mutation-negative cases of NSCLC (adenocarcinoma) as well as to evaluate the clinical characteristics of EGFR mutations and EML4-ALK fusions in EGFR mutation-negative cases of NSCLC.

\section{Materials and methods}

Patients with NSCLC, adenocarcinoma histology, whose tumors had been tested for EGFR mutational status by the amplification-refractory mutation system without enrichment of tumor samples during the period 2010 to 2014, were considered for this study. Stored tissue blocks from six centers were used for this study. Permission was obtained from the ethics committee at each center before the start of the study. Clinical characteristics and treatment details were collected from the patient's medical records in a de-identified manner. Formalin-fixed, paraffin-embedded tissue blocks were used for the mutation analysis. ALK mutation was tested in samples that were negative for EGFR mutation. ALK gene rearrangement was detected by fluorescence in situ hybridization (FISH) using the Vysis ALK Break Apart Rearrangement Probe Kit (Abbott Molecular, Abbott Park, IL, USA), which identifies all rearrangements of ALK irrespective of other fusion partners.

The Break Apart Rearrangement Probe contained two differently labeled probes on opposite sides of the breakpoint of the ALK gene. A SpectrumOrange (red) labeled $250 \mathrm{~kb}$ probe at the $3^{\prime}$ end of ALK and a SpectrumGreen (green) labeled $300 \mathrm{~kb}$ probe at the $5^{\prime}$ end of ALK. Sections of 4-6 $\mu \mathrm{m}$ thickness of formalin-fixed, paraffin-embedded tissue were cut and placed onto slides precoated with poly-L-lysine. The slides were deparaffinized, dehydrated, and then put into 10 $\mathrm{mM} \mathrm{HCl}$. After drying the slides, they were rinsed with $2.5 \%$ sodium thiocyanate solution and steamed in a microwave for 2 minutes. Next, the slides were put into $10 \mathrm{mM}$ sodium citrate buffer and boiled in the microwave for 4 minutes. The slides were immersed in a pepsin- $\mathrm{HCl}$ solution at $37^{\circ} \mathrm{C}$ for 25 minutes and then dehydrated. The probe mixture was added to the slide, the cover slip applied, the edges sealed, and the slide placed in a hybridizer at $80^{\circ} \mathrm{C}$ for 5 minutes to denature the probe. The hybridizer was sealed and the slides were incubated inside it at $37^{\circ} \mathrm{C}$ for $16-20$ hours to allow hybridization. Post-hybridization washes with saline sodium citrate were given and 4,6-diamidino-2-phenylindole (DAPI) counterstain was applied. The signals for each probe 
were evaluated under a fluorescence microscope using an oil immersion objective.

There were two patterns of ALK rearrangement. One was break-apart, where the red and green signals were split, and the distance between these two signals was $\geq 2$ signal diameters. ${ }^{16}$ In the other pattern, the green signal was lost, and only isolated or single red signals ( $3^{\prime}$ ALK) were observed, and these denote deletion in the $5^{\prime}$ ALK region in association with $2 \mathrm{p}$ inversion. ${ }^{16} \mathrm{~A}$ minimum of 50 tumor cells were counted, and cases were considered positive for ALK rearrangement when $>15 \%$ of the tumor cells showed split signals or single red signals; the rest of the cases were classified as ALK FISH negative. ${ }^{20-22}$ While scoring, normal lung tissue and lymphocyte nuclei were not counted. If no signals were detected, the test was repeated (if enough tissue was present). When the repeat test also showed no signals, the result of "test uninterpretable" was issued and the cause of uninterpretability reported. The FISH results were evaluated and the reasons for uninterpretable results investigated.

Statistical analysis was performed using Pearson's chisquared or Fisher's exact test - whichever was appropriate for categorical variables. Logistic regression was performed to compare the study groups. A two-sided $P<0.05$ was considered significant. Binary logistic regression with a single independent variable was performed; therefore, statistical correction has not been applied to the $P$-values reported in this paper. Statistical analysis was performed using SAS software (v 9.3; SAS Institute Inc., Cary, NC, USA).

\section{Results}

We included 500 NSCLC adenocarcinoma patients in this study across six centers. There were 337 (67.4\%) men and $163(32.6 \%)$ women with a median age of 58 years (range 21 to 90 years). Of the 500 patients, 250 (50\%) were neversmokers and $357(71.4 \%)$ had stage IV disease at the time of initial diagnosis. Baseline patient characteristics are presented in Table 1.

The results of molecular testing are shown in Table 2 and Figure 1. One hundred and sixty-four (32.8\%) blocks were positive for EGFR mutations, whereas 336 (67.2\%) were EGFR wild-type. Of the 336 EGFR-negative blocks, EML4-ALK fusion gene was present in 15 (4.5\%) patients, whereas 321 (95.5\%) tumors were EML4-ALK negative. The overall incidence of EML4-ALK fusion gene was 3\% $(15 / 500)$. Chemotherapy alone or in combination with radiotherapy and oral targeted therapy was the foremost treatment modality adopted to treat these patients.

The association of each of the individual factors with regard to EGFR and EML4-ALK fusion gene mutation is
Table I Summary of patient demographics and tumor characteristics $(\mathrm{N}=500)$

\begin{tabular}{ll}
\hline Characteristics & N (\%) \\
\hline Median age, years (range) & $58(21-90)$ \\
Sex & \\
Male & $337(67.4 \%)$ \\
Female & $163(32.6 \%)$ \\
Smoking & \\
Smokers & $164(32.8 \%)$ \\
Never-smokers & $250(50 \%)$ \\
Unknown & $86(17.2 \%)$ \\
Basis of diagnosis & \\
Histology & $500(100 \%)$ \\
Grade & \\
Well-differentiated & $18(3.6 \%)$ \\
Moderately differentiated & $53(10.6 \%)$ \\
Poorly differentiated & $91(18.2 \%)$ \\
Unknown & $338(67.6 \%)$ \\
Stage & \\
I & $4(0.8 \%)$ \\
II & $12(2.4 \%)$ \\
III & $58(11.6 \%)$ \\
IV & $357(71.4 \%)$ \\
Unknown & $69(13.8 \%)$ \\
\hline
\end{tabular}

shown in Table 3. While sex and cigarette smoking were significantly associated with EGFR mutation $(P<0.05)$ the EML4-ALK fusion gene mutation showed a significant association with sex and age $(P<0.05)$. There was a borderline association of cigarette smoking with EML4-ALK fusion gene mutation $(P=0.053)$.

Table 4 presents the distribution of EGFR and EML4ALK gene mutations across the study groups.

\section{Discussion}

The last decade has been an exciting period for pulmonary oncology research, wherein targeted therapies have improved median overall survival for patients with metastatic NSCLC to more than 1 year. ${ }^{3}$ Certain clinical subgroups, namely the never-smoking and minimal former-smoking patients, have seen even greater survival advantage. The uncontested benefit of EGFR TKIs for patients with EGFR activating mutations has clearly demonstrated the feasibility and power of tumor

Table 2 Results of molecular testing

\begin{tabular}{ll}
\hline Characteristics & $\mathbf{N}(\%)$ \\
\hline EGFR mutations & \\
$\quad$ Positive & $164(32.8 \%)$ \\
Wild-type & $336(67.2 \%)$ \\
EML4-ALK fusion gene & \\
Positive & $15(4.5 \%)$ \\
Wild-type & $321(95.5 \%)$ \\
\hline
\end{tabular}




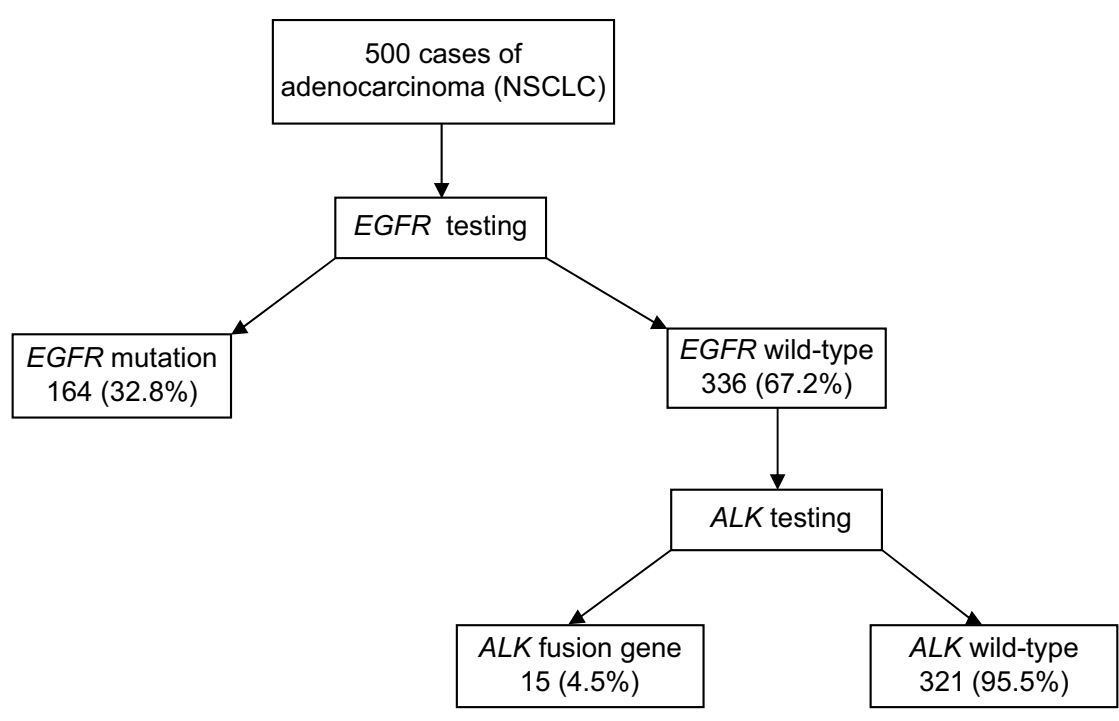

Figure I Molecular testing results.

Abbreviation: NSCLC, non-small-cell lung cancer.

molecular profiling as a guide for clinical treatment decisions and has paved the way for a new era of personalized treatment for NSCLC.

Studies across different ethnicities have reported the incidence of EGFR mutation in NSCLC at the rate of $10 \%-15 \%$ in North Americans and Europeans, ${ }^{23-25} 10 \%$ in AfricanAmericans, ${ }^{26} 24 \%$ in Koreans, ${ }^{27} 50.5 \%$ in Taiwanese, ${ }^{28} 26.3 \%$ in Japanese, ${ }^{29} 38.1 \%$ in Chinese, ${ }^{30}$ and $23.2 \%$ in Indian ${ }^{14}$ populations. Two other studies from India reported EGFR mutation frequencies of $25.9 \%$ and $51.8 \%$, respectively, along with female dominance. ${ }^{13,15}$ Regional differences have also been reported, with a higher incidence, at $65 \%$, in the southern Indian population as compared to $33 \%$ in northern Indian population. ${ }^{14,15,31-33}$ The incidence of EGFR mutations $(32.8 \%)$ in our study is close to the reported incidence in Asian patients (47\%) and much higher than that of Caucasian patients $(13 \%) .{ }^{34}$ Our study also confirms a higher incidence of EGFR mutation in the southern Indian population (47\%) as compared to the northern Indian population (27\%). The incidences of EGFR mutations in eastern and western Indian populations were $33 \%$ and $26 \%$, respectively. In the present study, a higher EGFR mutation rate was observed in females than in males ( $41.7 \%$ versus $28.5 \% ; P=0.003$ ), and the results were found to be statistically significant. This observation is consistent with previously published studies that have shown female sex dominance in cases of EGFR mutation. ${ }^{14,35,36}$ Although we included only those patients whose tumors had been tested for EGFR mutational status, the data for NSCLC in the never-smoker population (50\%) was in range of previously published reports from India $(29.4 \%$ to $54.7 \%) .^{14,15,37,38}$ The results of our study demonstrate a positive correlation of EGFR mutation in the never-smoker group as compared to smokers $(43.2 \%$ versus $17.7 \% ; P<0.001)$. Overall, the results of our study are in line with the findings of other

Table 3 Association of each of the individual factors vis-à-vis EGFR and EML4-ALK fusion gene mutations

\begin{tabular}{|c|c|c|c|c|c|}
\hline \multirow[t]{2}{*}{ Serial number } & \multirow[t]{2}{*}{ Variable } & \multicolumn{2}{|c|}{ EGFR mutations } & \multicolumn{2}{|c|}{$\begin{array}{l}\text { EML4-ALK fusion gene } \\
\text { mutations }\end{array}$} \\
\hline & & $\chi^{2}$ & $P$-value & $\chi^{2}$ & $P$-value \\
\hline 1 & Sex & 8.7257 & 0.0031 & 7.2785 & 0.007 \\
\hline 2 & Age & 1.1984 & 0.5493 & 23.6355 & $<0.0001$ \\
\hline 3 & Cigarette smoking & 29.1236 & $<0.000$ I & 3.2547 & 0.0533 \\
\hline 4 & Tobacco chewing & 0.104 & $0.747 \mid$ & 3.3185 & 0.2344 \\
\hline 5 & Alcohol intake & 1.2887 & 0.2563 & $3.4|3|$ & 0.2295 \\
\hline 6 & Grade & 1.5262 & 0.4662 & 2.401 & 0.428 \\
\hline 7 & Stage of disease & 11.4349 & 0.0221 & 1.1379 & 0.1769 \\
\hline 8 & Performance status & 8.4289 & 0.1887 & 6.6411 & 0.2288 \\
\hline
\end{tabular}


Table 4 Distribution of EGFR and EML4-ALK gene mutations

\begin{tabular}{|c|c|c|c|c|c|c|}
\hline \multirow[t]{2}{*}{ Variable } & \multicolumn{3}{|l|}{ EGFR } & \multicolumn{3}{|c|}{ EML4-ALK fusion gene } \\
\hline & Wild-type n (\%) & Mutated n (\%) & $P$-value & Wild-type n (\%) & Mutated n (\%) & $P$-value \\
\hline Sex & & & 0.003 & & & 0.009 \\
\hline Female & $95(58.3)$ & $68(41.7)$ & & $86(90.5)$ & $9(9.5)$ & \\
\hline Male & $24 \mid(7 \mid .5)$ & $96(28.5)$ & & $235(97.5)$ & $6(2.5)$ & \\
\hline Age, years & & & 0.549 & & & 0.0006 \\
\hline $20-40$ & $25(67.6)$ & $12(32.4)$ & & $19(76)$ & $6(24)$ & \\
\hline $40-60$ & $153(64.8)$ & $83(35.2)$ & & $146(96.1)$ & $6(3.9)$ & \\
\hline$>60$ & $158(69.6)$ & $69(30.4)$ & & $156(98.1)$ & $3(1.9)$ & \\
\hline Smoking history & & & $<0.001$ & & & 0.151 \\
\hline Never-smokers & $142(56.8)$ & $108(43.2)$ & & I 34 (94.4) & $8(5.6)$ & \\
\hline Smokers & $135(82.3)$ & $29(17.7)$ & & I $32(97.1)$ & $4(2.9)$ & \\
\hline Unknown & $59(68.6)$ & $27(31.4)$ & & $53(91.4)$ & $5(8.6)$ & \\
\hline Stage & & & 0.346 & & & 0.644 \\
\hline I & $4(80)$ & I (20) & & $4(100)$ & 0 & \\
\hline II & $6(54.5)$ & $5(45.5)$ & & $6(100)$ & 0 & \\
\hline III & $60(81.1)$ & $14(18.9)$ & & $59(98.3)$ & $\mathrm{I}(\mathrm{I} .7)$ & \\
\hline IV & $246(63.6)$ & $|4|(36.4)$ & & $236(95.9)$ & $10(4.1)$ & \\
\hline Unknown & $20(87)$ & $3(13)$ & & $16(80)$ & $4(20)$ & \\
\hline
\end{tabular}

Indian studies, with the advantage of having data from all the four geographical regions (east, west, north, and south) of the country.

EML4 ALK fusion protein represents another molecular type, and, when inhibited by ALK and c met inhibitors in a selected subset of patients, has shown response rates of more than $60 \% .{ }^{4}$ The initial reports of EML4 ALK fusion protein date back to 2007, when a few studies reported NSCLC harboring a fusion gene between EML4 and the intracellular domain of ALK. ${ }^{5,39}$ Crizotinib is an inhibitor of receptor tyrosine kinases including ALK, hepatocyte growth factor receptor (HGFR), c-Met, and Recepteur d'Origine Nantais (RON). ${ }^{9}$ Unlike with EGFR, there are very few reports on EML4 ALK mutation across different ethnicities. The overall incidence of ALK gene rearrangements in NSCLC is estimated to be $3 \%$, with an incidence of up to $13 \%$ in East Asian populations. ${ }^{5,8}$ Among 226 NSCLC tumor samples available in an East Asian population, the EML4ALK fusion gene was found in about $5 \%$ of cases, mostly in young patients who were never-smokers. ${ }^{8}$ Another study, by Zhang et al reported a $13 \%$ incidence of ALK mutations in Chinese NSCLC patients, particularly in those with adenocarcinoma lacking EGFR/K-RAS mutation. ${ }^{6}$ In this study, EML4-ALK and EGFR mutations were found to be mutually exclusive, suggesting ALK mutations as a potential therapeutic target in EGFR wild-type lung cancer. A perspective review on the potential of crizotinib in NSCLC by Bang reports the prevalence of ALK fusion gene in unselected and adenocarcinoma-enriched patient populations across 14 studies as $3.4 \%$ and $4.5 \%$, respectively. ${ }^{40}$ The total numbers of patients across 14 studies included in this review were 2,864 and 1,820 for the unselected and adenocarcinoma-enriched patient populations, respectively.

To date, there is only one published report from India on EML4 ALK mutations demonstrating a positivity of $2.7 \% .{ }^{16}$ Our study confirms that EML4-ALK gene fusions are present in lung adenocarcinomas from Indian patients, and the 3\% incidence of EML4-ALK gene fusion in EGFR mutation-negative cases is similar to what has been observed in other Western and Asian populations. ${ }^{40-42}$ In the present study, a higher EML4-ALK fusion gene mutation rate was observed in females than in males $(9.5 \%$ versus $2.5 \% ; P=0.009$ ), and the results were found to be statistically significant. Age was categorized in three groups in this study, and a higher EML4-ALK fusion gene mutation rate (24\%) was observed in the youngest age group, of 20-40 years $(P=0.006)$, as compared to $3.9 \%$ and $1.9 \%$ in the age groups of 40-60 years and $>60$ years, respectively. This finding is consistent with previously published reports on EML4 ALK fusion gene mutations.

\section{Conclusion}

Our study reports the first multicenter data on EML4 ALK fusion gene mutations in EGFR mutation-negative Indian NSCLC patients, with the limitation of being a retrospective study that lacks survival data. However, it establishes the importance of EML4 ALK fusion gene testing in Indian NSCLC population to detect tumors harboring ALK rearrangements which can benefit from new targeted therapies. Prospective studies to investigate the survival benefit are warranted. 


\section{Acknowledgment}

This study was supported by Pfizer's Investigator Initiated Research Grant.

\section{Disclosure}

The authors report no conflicts of interest in this work. No benefits in any form have been received or will be received from a commercial party related directly or indirectly to the subject of this article.

\section{References}

1. Jemal A, Siegel R, Ward E, et al. Cancer statistics, 2008. CA Cancer J Clin. 2008;58:71-96.

2. Reck M, Heigener DF, Mok T, Soria JC, Rabe KF. Management of non-small-cell lung cancer: recent developments. Lancet. 2013;382:709-719.

3. Okamoto I, Mitsudomi T, Nakagawa K, Fukuoka M. The emerging role of epidermal growth factor receptor (EGFR) inhibitors in first-line treatment for patients with advanced non-small cell lung cancer positive for EGFR mutation. Ther Adv Med Oncol. 2010;2:301-307.

4. Tsao AS, Papadimitrakopoulou VA. The future of NSCLC: molecular profiles guiding treatment decisions. Oncology (Williston Park). 2011;25:607, 614 .

5. Soda M, Choi YL, Enomoto M, et al. Identification of the transforming EML4-ALK fusion gene in non-small-cell lung cancer. Nature. 2007;448:561-566.

6. Zhang X, Zhang S, Yang X, et al. Fusion of EML4 and ALK is associated with development of lung adenocarcinomas lacking EGFR and KRAS mutations and is correlated with ALK expression. Mol Cancer. 2010;9:188.

7. Kim D, Ahn M, Yang P, et al. Updated results of a global phase II study with crizotinin in advanced ALK-positive non-small cell lung cancer (NSCLC). Ann Oncol. 2012;23:Abstr 1230 PD.

8. Wong DW, Leung EL, So KK, et al; University of Hong Kong Lung Cancer Study Group. The EML4-ALK fusion gene is involved in various histologic types of lung cancers from nonsmokers with wild-type EGFR and KRAS. Cancer. 2009;115:1723-1733.

9. Kwak EL, Bang YJ, Camidge DR, et al. Anaplastic lymphoma kinase inhibition in non-small-cell lung cancer. $N$ Engl J Med. 2010;363(18):1693-1703.

10. Shaw AT, Yeap BY, Solomon BJ, et al. Impact of crizotinib on survival in patients with advanced, ALK-positive NSCLC compared with historical controls. J Clin Oncol. 2011;29:(suppl; abstr 7507).

11. Crino L, Kim D, Riely GJ, et al. Initial Phase II results with crizotinib in advanced $A L K$-positive non-small cell lung cancer (NSCLC): PROFILE 1005. J Clin Oncol. 2011;29:(suppl; abstr 7514).

12. Shaw AT, Kim DW, Nakagawa K, et al. Crizotinib versus chemotherapy in advanced ALK-positive lung cancer. $N$ Engl J Med. 2013;368(25):2385-2394.

13. Sahoo R, Harini VV, Babu VC, et al. Screening for EGFR mutations in lung cancer, a report from India. Lung Cancer. 2011;73(3):316-319.

14. Chougule A, Prabhash K, Noronha V, et al. Frequency of EGFR mutations in 907 lung adenocarcinoma patients of Indian ethnicity. PLoS One. 2013;8(10):e76164.

15. Doval DC, Azam S, Batra U, et al. Epidermal growth factor receptor mutation in lung adenocarcinoma in India: a single center study. J Carcinog. 2013;12:12.

16. Desai SS, Shah AS, Prabhash K, Jambhekar NA. A year of anaplastic large cell kinase testing for lung carcinoma: pathological and technical perspectives. Indian J Cancer. 2013;50(2):80-86.

17. Tanaka H, Hayashi A, Morimoto T, et al. A case of lung adenocarcinoma harboring EGFR mutation and EML4-ALK fusion gene. BMC Cancer. 2012;12:558.
18. Lee JK, Kim TM, Koh Y, et al. Differential sensitivities to tyrosine kinase inhibitors in NSCLC harboring EGFR mutation and ALK translocation. Lung Cancer. 2012;77(2):460-463.

19. Popat S, Vieira de Araújo A, Min T, et al. Lung adenocarcinoma with concurrent exon 19 EGFR mutation and ALK rearrangement responding to erlotinib. J Thorac Oncol. 2011;6(11):1962-1963.

20. Varella-Garcia M, Cho Y, Lu X, et al. ALK gene rearrangements in unselected caucasians with non-small cell lung carcinoma (NSCLC). J Clin Oncol. 2010;28:18s(suppl; abstr 10533).

21. Shaw AT, Yeap BY, Mino-Kenudson M, et al. Clinical features and outcome of patients with non-small-cell lung cancer who harbor EML4ALK. J Clin Oncol. 2009;27:4247-4253.

22. Rodig SJ, Mino-Kenudson M, Dacic S, et al. Unique clinicopathologic features characterize ALK-rearranged lung adenocarcinoma in the western population. Clin Cancer Res. 2009;15:5216-5223.

23. Lynch TJ, Bell DW, Sordella R, et al. Activating mutations in the epidermal growth factor receptor underlying responsiveness of non-small-cell lung cancer to gefitinib. N Engl J Med. 2004;350: 2129-2139.

24. Paez JG, Jänne PA, Lee JC, et al. EGFR mutations in lung cancer: correlation with clinical response to gefitinib therapy. Science. 2004; 304:1497-1500

25. Dogan S, Shen R, Ang DC, et al. Molecular epidemiology of EGFR and KRAS mutations in 3,026 lung adenocarcinomas: higher susceptibility of women to smoking-related KRAS-mutant cancers. Clin Cancer Res. 2012;18:6169-6177.

26. Cortes-Funes H, Gomez C, Rosell R, et al. Epidermal growth factor receptor activating mutations in Spanish gefitinib-treated non-small-cell lung cancer patients. Ann Oncol. 2005;16:1081-1086.

27. Jang TW, Oak CH, Chang HK, Suo SJ, Jung MH. EGFR and KRAS mutations in patients with adenocarcinoma of the lung. Korean J Intern Med. 2009;24:48-54.

28. Wu SG, Gow CH, Yu CJ, et al. Frequent epidermal growth factor receptor gene mutations in malignant pleural effusion of lung adenocarcinoma. Eur Respir J. 2008;32:924-930.

29. Usui K, Ushijima T, Tanaka Y, et al. The frequency of epidermal growth factor receptor mutation of nonsmall cell lung cancer according to the underlying pulmonary diseases. Pulm Med. 2011;2011:290132.

30. Huang YS, Yang JJ, Zhang XC, et al. Impact of smoking status and pathologic type on epidermal growth factor receptor mutations in lung cancer. Chin Med J (Engl). 2011;124:2457-2460.

31. Aggarwal S, Patil S, Minhans S, Pungliya M, Soumitra N. A study of EGFR mutation in nonsmoker NSCLC: striking disparity between north and south India patients. J Clin Oncol. 2012;30(suppl; abstr e18041).

32. Pungliya M, Sachin M, Soumittra N, Shekar P, Shyam A. A study of incidence of EGFR mutations in non-smoker adenocarcinoma of the lung: disparity between north and south indian patients. J Cancer Ther Res. 2014;3:4.

33. Mehta J. Molecular epidemiology of epidermal growth factor receptor mutations in lung cancers in Indian population. Indian J Cancer. 2013;50(2):102-106.

34. Sekine I, Yamamoto N, Nishio K, Saijo N. Emerging ethnic differences in lung cancer therapy. Br J Cancer. 2008;99:1757-1762.

35. Smits AJ, Kummer JA, Hinrichs JW, et al. EGFR and KRAS mutations in lung carcinomas in the Dutch population: increased EGFR mutation frequency in malignant pleural effusion of lung adenocarcinoma. Cell Oncol (Dordr). 2012;35:189-196.

36. Tanaka T, Matsuoka M, Sutani A, et al. Frequency of and variables associated with the EGFR mutation and its subtypes. Int J Cancer. 2010; 126:651-655.

37. Krishnamurthy A, Vijayalakshmi R, Gadigi V, Ranganathan R, Sagar TG. The relevance of "Nonsmoking-associated lung cancer" in India: a single-centre experience. Indian J Cancer. 2012;49:82-88.

38. Malik PS, Sharma MC, Mohanti BK, et al. Clinico-pathological profile of lung cancer at AIIMS: a changing paradigm in India. Asian Pac J Cancer Prev. 2013;14:489-494. 
39. Rikova K, Guo A, Zeng Q, et al. Global survey of phosphotyrosine signaling identifies oncogenic kinases in lung cancer. Cell. 2007;131:1190-1203.

40. Bang YJ. The potential for crizotinib in non-small cell lung cancer: a perspective review. Ther Adv Med Oncol. 2011;3(6):279-291.

41. Fukui T, Yatabe Y, Kobayashi Y, et al. Clinicoradiologic characteristics of patients with lung adenocarcinoma harboring EML4-ALK fusion oncogene. Lung Cancer. 2012;77:319-325.
42. Paik JH, Choi CM, Kim H, et al. Clinicopathologic implication of ALK rearrangement in surgically resected lung cancer: a proposal of diagnostic algorithm for ALK-rearranged adenocarcinoma. Lung Cancer. 2012;76:403-409.

\section{Publish your work in this journal}

OncoTargets and Therapy is an international, peer-reviewed, open access journal focusing on the pathological basis of all cancers, potential targets for therapy and treatment protocols employed to improve the management of cancer patients. The journal also focuses on the impact of management programs and new therapeutic agents and protocols on

\section{Dovepress}

patient perspectives such as quality of life, adherence and satisfaction. The manuscript management system is completely online and includes a very quick and fair peer-review system, which is all easy to use. Visit http://www.dovepress.com/testimonials.php to read real quotes from published authors.

Submit your manuscript here: http://www.dovepress.com/oncotargets-and-therapy-journal 